\title{
OPTIMIZATION PARAMETER FOR PRODUCTION OF PROTOCORM- LIKE BODY AND GROWTH OF GRAMMATOPHYLLUM SPECIOSUM
}

\author{
Zuraida Ab Rahman ${ }^{1}$, Ayu Nazreena Othman ${ }^{1}$, Amirah Balqis Amir Amran $^{2}$ and Nur Najwa \\ Arifah Basiron ${ }^{1}$ \\ ${ }^{1}$ Biotechnology \& Nanotechnology Research Centre, Malaysian Agricultural Research and Development Institute, MARDI \\ HQ, Persiaran MARDIUPM, 43400, Serdang Selangor, Malaysia \\ ${ }^{2}$ School of Agriculture Science \& Biotechnology, Faculty of Bioresources and Food Industry, Universiti Sultan Zainal Abidin, \\ Besut Campus, 22200, Besut, Terengganu, Malaysia
}
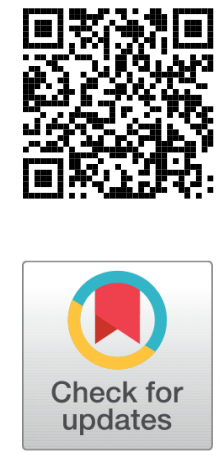

Received 5 July 2021

Accepted 20 July 2021

Published 31 July 2021

Corresponding Author

Zuraida Ab Rahman, azuraida@m

ardi.gov.my

DOI 10.29121/

granthaalayah.v9.i7.2021.4099

Funding: This research received no specific grant from any funding agency in the public, commercial, or not-for-profit sectors.

Copyright: (C) 2021 The Author(s). This is an open access article distributed under the terms of the Creative Commons Attribution License, which permits unrestricted use, distribution, and reproduction in any medium, provided the original author and source are credited.

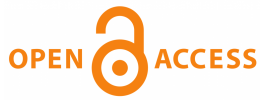

\section{ABSTRACT}

Micropropagation of orchids are often through the production of Protocorm Like Bodies (PLBs) and this research conducted a study to discover the optimal condition for the growth of Protocorm Like Bodies (PLBs) and also plantlets regeneration of Grammatophyllum speciosum Several aspects such as different carbon sources (sucrose, maltose) and the presence of charcoal alongside with the variety of concentration of agar were taken into account for the optimization. This study discovered that the $30 \mathrm{~g} / \mathrm{L}$ of sucrose in $1 \mathrm{mg} / \mathrm{L}$ of BAP was superior in producing heavy PLBs. However, the trend differs in the number of plantlets where maltose $(5 \mathrm{~g} / \mathrm{L})$ is seen to produce a higher number of plantlets compared to sucrose. Charcoal plays an important role in the growth of PLBs where the heaviest PLBs were recorded in the medium supplemented with 0.20 $\%$ of charcoal along with $4.5 \mathrm{~g}$ of agar. Vice versa relationship was recorded for the number of plantlets where without charcoal in $4.5 \mathrm{~g}$ of agar produce the highest number of plantlets.

Keywords: Grammatophyllum Speciosum, Plbs, Carbon Sources

\section{INTRODUCTION}

Grammatophyllum speciosum can be categorized under the family of Orchidaceae, which contains a diverse range of flowering plants with over 100,000 hybrids resulted from artificial pollination Cardoso et al. (2020). Classified as the largest orchid in the world, Grammatophyllum speciosum is commonly known as tiger orchid and is native to Malaysia, Indonesia, the Philippines, and Thailand. A single tiger orchid plant can produce up to 7000 flowers in a season, however, it only blooms once every two to four years Chee (2015). Therefore, micropropagation is one of the initiatives to continue producing tiger orchids throughout the whole year. 
Carbon dioxide is essential for the growth of plants and unfortunately, when cultured in vitro, the carbon dioxide concentration is generally low PIMSEN and KANCHANAPOOM (2011), and to counter this condition, carbon sources such as sucrose and maltose are essential in providing sufficient carbon dioxide for the longevity of plants or in this case the tiger orchid. In order to encourage seed germination which will further develop into protocorm-like bodies which eventually result in plant regeneration of tiger orchids, optimization of growth conditions for tiger orchids is very much needed.

Conversely, other components such as agar and also charcoal are also prominent to support in vitro growth of tiger orchids. In tissue culture, activated charcoal is often used to induce the growth and development of plants and this is due to the adsorption properties of the charcoal and this can also help to prevent browning in in vitro cultures because activated charcoal will adsorb solutes until adsorption equilibrium is reached Thomas (2008). Other than that, agar is important in producing solidified media to support the growth of plants. However, the exact or optimal concentration of agar and charcoal for tiger orchids is still scarce which is why this study was conducted.

\section{MATERIALS AND METHODS}

\subsection{PLANT MATERIALS}

The pods of tiger orchid were assembled from the plants that were cultivated and were proceed with surface sterilization with the usage of $50 \%$ ethanol followed by immersion in $15 \%(\mathrm{v} / \mathrm{v})$ sodium hypochlorite $(\mathrm{NaOCl})$ solution $15 \%(\mathrm{v} / \mathrm{v})$ that also contained $0.5 \%(\mathrm{v} / \mathrm{v})$ Tween-20 for 10 minutes. The pods were then rinsed with sterile distilled water and were cut vertically over a sterile Petri-dish. Seeds of Grammatophyllum speciosum were then removed before placing in a medium for germination (Figure 5 a). The medium used for germination was Murashige and Skoog (MS) supplemented with $5 \mathrm{mg} / \mathrm{L}$ of BAP. The period of seed germination of Grammatophyllum speciosum was about 6 months of culture with the culture maintained in a culture room supplemented with fluorescent light with a light intensity of 3000 lux and a photoperiodic period of 16 hours at $25 \pm 2{ }^{\circ} \mathrm{C}$. After 6 months, the germinated seeds ( Figure $5 \mathrm{~b}$ ) were used for the experiment.

\subsection{EFFECT OF CARBON SOURCE, CHARCOAL, AND AGAR}

After 6 months of culture, the seed germinated in the medium supplemented with 5 $\mathrm{mg} / \mathrm{L}$ BAP in MS media alongside with $30 \%$ sucrose were chosen to proceed in the next part of the experiment which is to study the effect of various carbon sources and also the effect of charcoal and agar. To study the effect of different carbon sources, the seed-derived protocorms were cultured for a month on a treatment medium containing Murashige and Skoog (MS) and supplied with different concentrations of carbon sources; sucrose $15 \mathrm{~g} / \mathrm{L}$ (S15), sucrose $30 \mathrm{~g} / \mathrm{L}$ (S30), maltose $5 \mathrm{~g} / \mathrm{L}$ (M5) and maltose 
$10 \mathrm{~g} / \mathrm{L}$ (M10) with each of the carbon sources supplemented with either $1 \mathrm{mg} / \mathrm{L}$ or 5 $\mathrm{mg} / \mathrm{L}$ of BAP. After two months, several data were collected such as the fresh weight of PLBs ( $\mathrm{g}$ ) and the number of plantlets formed in response to different types and concentrations of carbon sources.

To study the effect of charcoal and agar, protocorms of Grammatophyllum speciosum were also cultured on the various concentrations of agar which are $3 \mathrm{~g} / \mathrm{L}, 4.5 \mathrm{~g} / \mathrm{L}$ and the highest would be $6 \mathrm{~g} / \mathrm{L}$ of agar for a month. On top of that, different percentages of charcoal $(0 \%, 0.10 \%, 0.20 \%)$ were also applied in each of the concentrations of agar stated previously $(3 \mathrm{~g} / \mathrm{L}, 4.5 \mathrm{~g} / \mathrm{L}, 6 \mathrm{~g} / \mathrm{L})$. Parameters were measured after two months which include the fresh weight of PLBs and the number of plantlets.

\subsection{ACCLIMATIZATION}

Shoots of Grammatophyllum speciosum that are in the length of $4-5 \mathrm{~cm}$ were removed from the cultured flask. The shoots were then rinsed under running tap water several times and then proceed with individual plantlets being transplanted into polybags with a 1:1 ratio of topsoil and organic soil. The individual plants were then kept under $75 \%$ shading under the glasshouse along with regular watering.

\section{RESULTS AND DISCUSSION}

As seen in Figure 1, the heaviest PLBs (11.3 g) are the PLBs cultured on mediums containing sucrose $30 \mathrm{~g} / \mathrm{L}$ as the carbon source and supplemented with $1 \mathrm{mg} / \mathrm{L}$ of BAP (Figure $5 \mathrm{c}$, d). However, PLBs in $30 \mathrm{~g} / \mathrm{L}$ sucrose with $5 \mathrm{mg} / \mathrm{L}$ of BAP only differ slightly weighing at $11.1 \mathrm{~g}$. On the other hand, from this study, $10 \mathrm{~g} / \mathrm{L}$ of maltose are seen to be responding poorly in terms of the weight of PLBs. It can be seen from Figure 1 that $1 \mathrm{mg} / \mathrm{L}$ of BAP with $10 \mathrm{~g} / \mathrm{L}$ of maltose as a carbon source is only able to produce $5.2 \mathrm{~g}$ of PLBs. Despite having the same concentration of BAP $(1 \mathrm{mg} / \mathrm{L})$, the gap between $30 \mathrm{~g} / \mathrm{L}$ of sucrose and $10 \mathrm{~g} / \mathrm{L}$ of maltose regarding the weight of PLBs is vast. A similar trend can be seen for $5 \mathrm{mg} / \mathrm{L}$ of BAP where maltose $(10 \mathrm{~g} / \mathrm{L})$ recorded the lowest reading for the weight of PLBs (8.1g) among other carbon sources supplemented with $5 \mathrm{mg} / \mathrm{L}$ of BAP. Therefore, optimal carbon sources for the growth of PLBs for tiger orchid sucrose $30 \mathrm{~g} / \mathrm{L}$ in $1 \mathrm{mg} / \mathrm{L}$ of BAP. Sucrose with $0 \%$ potato homogenate is seen in a study by Murdad et al. (2010), to produce the highest growth of protocorms among other mediums cultured in sucrose but with the combination of several percentages of potato homogenate. This can be said that sucrose alone, able to promote the growth of protocorm. However, Sopalun et al. (2010) recorded maltose produced the highest relative growth of PLBs of tiger orchid but the concentration of maltose used in the study was only $2 \%$ and the sucrose used in the study was also only $2 \%$. On the other hand, as reported by Zha et al. (2007), sucrose at 35 $\%$ was recorded for the heaviest PLBs $(19.01 \mathrm{~g} / \mathrm{L})$ similar to the findings from this study although with a slight difference. Nevertheless, this still supports the fact that compared to other sugars, sucrose is suitable for producing PLBs. Besides that, San- 
jaya et al. (2007) reported that sucrose along with fructose is superior in producing PLBs. Other than that, to further support the results as seen in Figure 1 , in the same study, the inability of maltose to produce PLBs was also reported in the study Sanjaya et al. (2007). On top of that, the same sucrose concentration which is $30 \mathrm{~g} / \mathrm{L}$ was also found out to be optimal for protocorms development of orchids were reported by Júnior et al. (2014) which further verify the results obtained from this study.

On the contrary, for the number of plantlets in Figure 2 , maltose seems to produce the highest number of plantlets (Figure 5 ). among other carbon sources (31) alongside $1 \mathrm{mg} / \mathrm{L}$ of BAP. However, the previous reading was for $5 \mathrm{~g} / \mathrm{L}$ of maltose and maltose $10 \mathrm{~g} / \mathrm{L}$ still are not suitable in producing either plantlets of Grammatophyllum speciosum or PLBs. As for $1 \mathrm{mg} / \mathrm{L}$ of BAP with $30 \mathrm{~g} / \mathrm{L}$ of sucrose that had eminent result in the weight of PLBs seem to produce only 24 plantlets. Hence, it can be concluded that $5 \mathrm{~g} / \mathrm{L}$ of maltose is recommendable in producing plantlets in abundance. According to Sopalun et al. (2010), plantlets regeneration of Grammatophyllum speciosum in $1 \mathrm{mg} / \mathrm{L}$ of BAP with $2.0 \mathrm{mg} / \mathrm{L}$ of NAA are the best plant growth regulators for plantlets regeneration. This somehow proves that $1 \mathrm{mg} / \mathrm{L}$ of BAP is suitable for plantlets regeneration of tiger orchids. As for maltose, similar findings can be seen in a study by Luo et al. (2009) where maltose is superior in plantlets regeneration. However, contradict to this study, Luo et al. (2009) recorded that 10 $\mathrm{g} / \mathrm{L}$ of maltose regenerates the highest number of plantlets. The reason for this may be because Luo et al. (2009) conducted regeneration from protocorms for Dendrobium huoshanense which comes from the same family as Grammatophyllum speciosum. Nevertheless, this still does not cancel the fact that maltose is optimal for regeneration. Besides that, from a study by Orshinsky et al. (1990), maltose is seen to be producing green shoot regeneration compared to sucrose. Therefore, it can be said that maltose is suitable for plant regeneration, and as for Grammatophyllum speciosum, this study found out that $5 \mathrm{~g} / \mathrm{L}$ of maltose is optimal for the regeneration of plantlets.

As for Figure 3 , this study found out that the heaviest PLBs weighing $15.2 \mathrm{~g}$ are cultured on $4.5 \mathrm{~g}$ agar alongside the highest percentage of charcoal $(0.20 \%)$. The lowest reading for the weight of PLBs was cultured on $3 \mathrm{~g} / \mathrm{L}(5.1 \mathrm{~g})$ with no charcoal or $0 \%$. PLBs cultured in $0 \%$ charcoal showed the lowest reading out of all percentages of charcoal regardless of the agar while PLBs cultured on $0.20 \%$ agar contributed to the heaviest agar when compared with other percentages of charcoal. This is expected since charcoal accelerates the formation of PLBs which is reflected in Figure 3 . Therefore, this study suggested that the optimal condition to culture PLBs would be on $4.5 \mathrm{~g}$ of agar with the combination of $0.20 \%$ of charcoal. Conversely, the opposite trend was spotted in Figure 4 where Grammatophyllum speciosum cultured on $0 \%$ charcoal showed the highest number of plantlets (37) but the concentration of agar remained at $4.5 \mathrm{~g}$ same as the results in Figure 3 . As for $0.20 \%$ of charcoal, the results showed the lowest reading which are $14(6 \mathrm{~g} / \mathrm{L}), 15(4.5 \mathrm{~g})$, and 17 ( $3 \mathrm{~g} / \mathrm{L})$. The results for $0.20 \%$ charcoal showed an opposite relationship between 


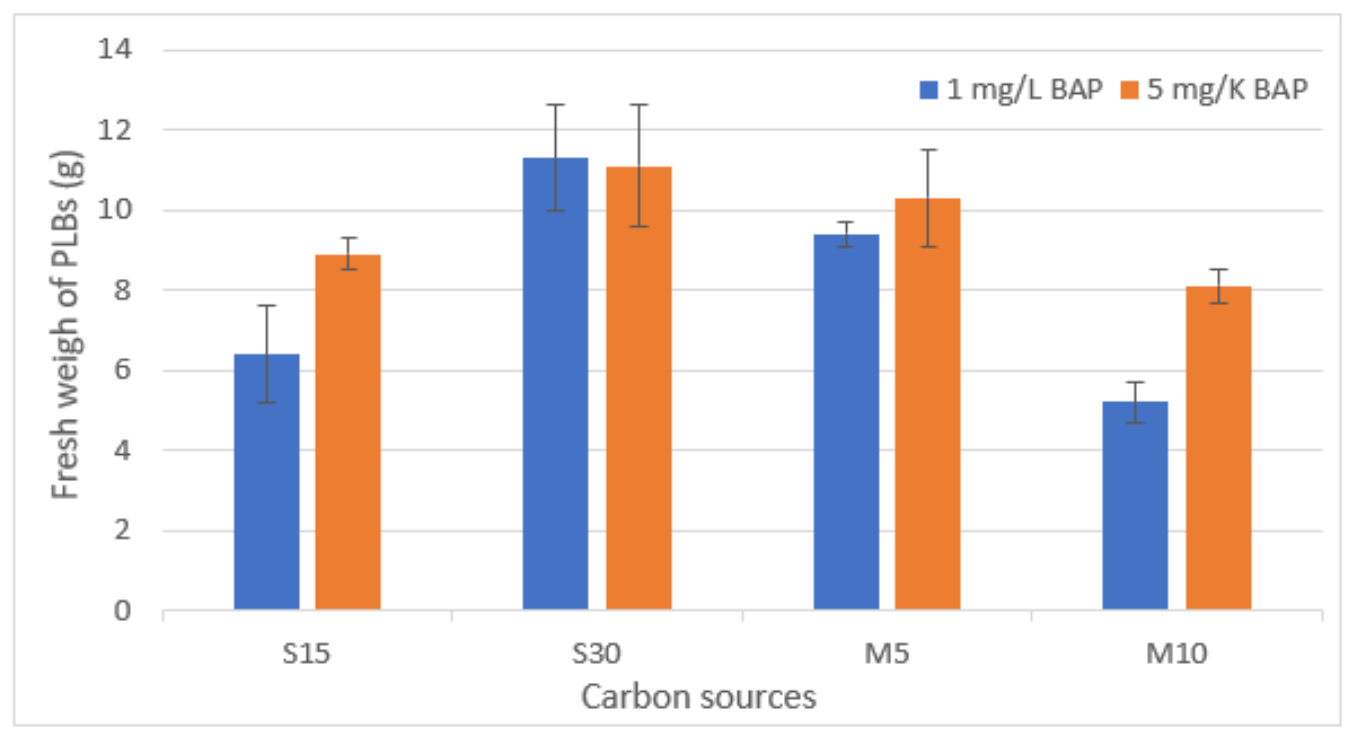

Figure 1 Effect of carbon sources on fresh weight of PLBs

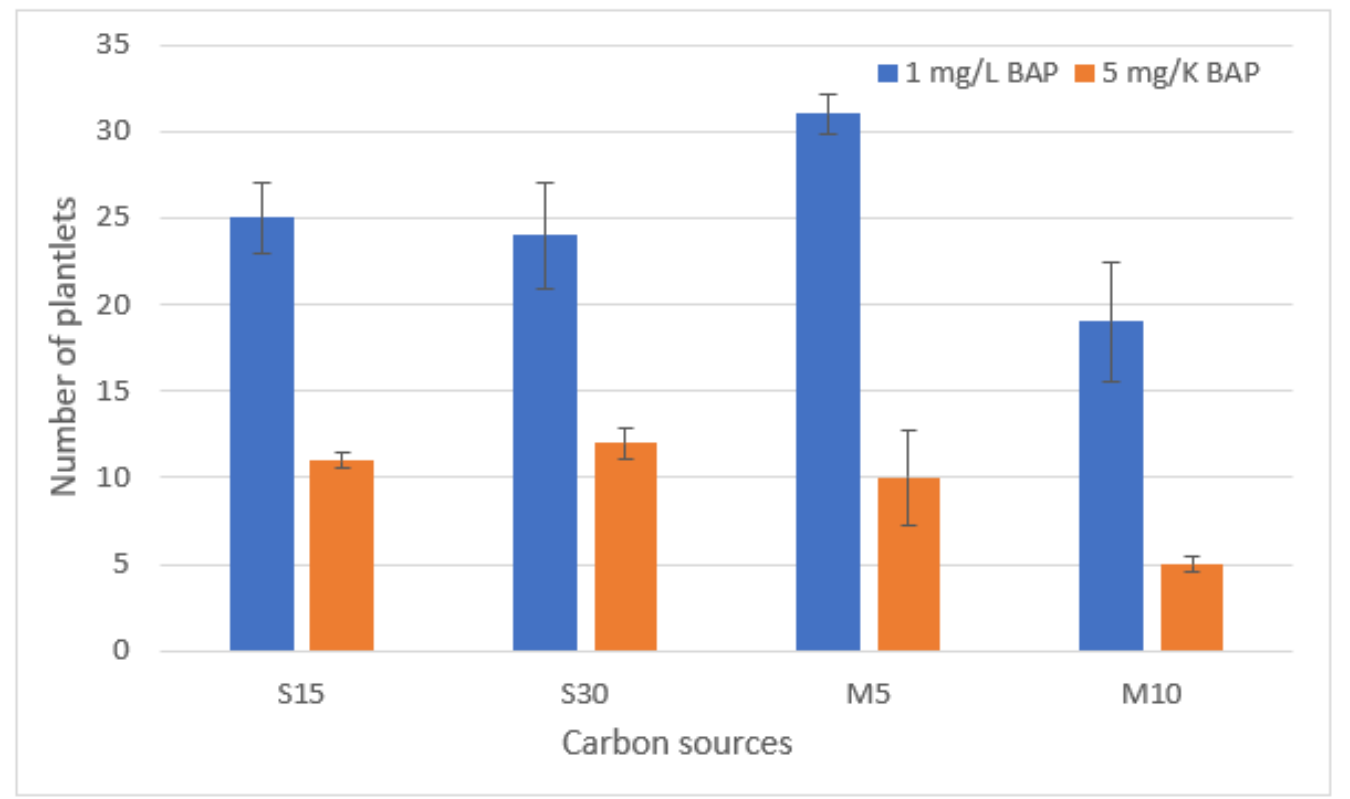

Figure 2 Effect of carbon sources on the number of plantlets 


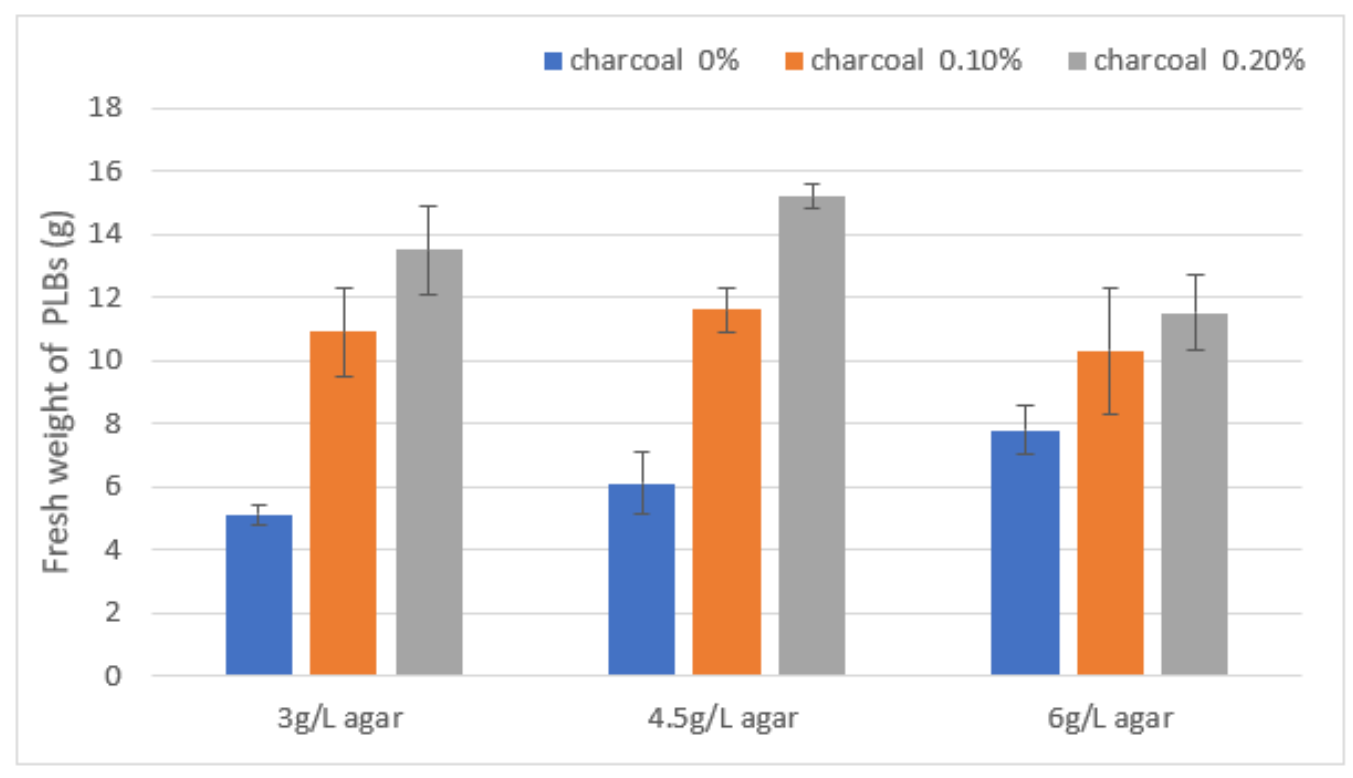

Figure 3 Effect of charcoal and agar on fresh weight of PLBs

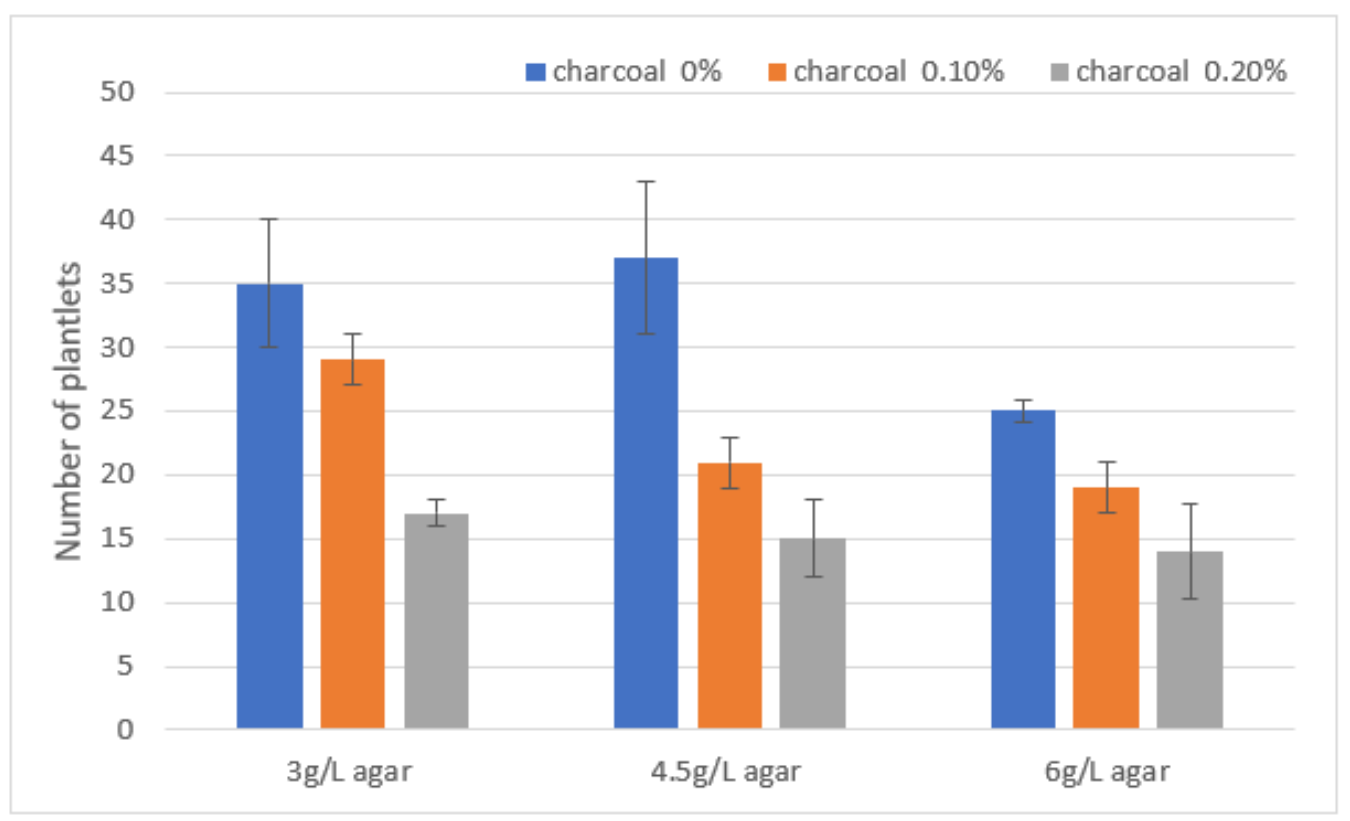

Figure 4 Effect of charcoal and agar on number of plantlets 
the percentage of charcoal and the concentration of agar where there is a steady and slight decrease in the number of plantlets when there is an increase in the concentration of agar. The obtained plantlets were transplanted to pots filled with medium. They were maintained at about $70 \%$ relative humidity in the greenhouse with $75 \%$ shading. A survival rate 95\% was achieved after 2 months (Figure $5 \mathrm{~h}$ ).

A study by Koene et al. (2019) recommended adding charcoal due to the adsorption properties where the addition of charcoal will not only promotes rooting and elongation but also have the potential of reducing the cost of seedlings. Contrarily, the study by Koene et al. (2019) reported that the absence of charcoal stunted plantlet growth, and this may be due to the fact that the medium used was Woody Plant Medium (WPM) and half-strength MS medium instead of MS medium. WPM and half-strength MS medium have significantly lower salt concentrations than full strength MS medium, therefore, the addition of charcoal is necessary for providing ionic balance in the medium which in return promotes plantlets growth in WPM and half-strength MS medium. However, the foundation in providing optimal medium condition is based on nitrogen concentration along with the ammonium/nitrate ratio Koene et al. (2019), hence which explains why different mediums need different optimization. Nevertheless, a study by Sipayung et al. (2018) stated that activated charcoal does not provide significant changes to the growth of plantlets of orchids within two to seven months of culturing in MS media. Other than that, the recommendation of adding charcoal in protocorms development was also supported by the study of Te-Chato et al. (2012) whereby $0.2 \%$ of charcoal reduce the browning in the medium for plantlets regeneration. One of the aspects touched in a study by Debergh (1983) was the effects of different concentrations of agar, and the results showed similar findings from Figure 4 where the increased concentration of agar would decrease the propagation of plantlets resulting in a lower number of plantlets with the exception for the cultures on $0 \%$ charcoal. However, as reported by Debergh (1983), there was a significant difference in the ions and conductivity of the medium where a higher concentration of salt contains higher ions which cause stress to plants which reflects the lesser number of plantlets in $6 \mathrm{~g} / \mathrm{L}$ of agar. Therefore, $4.5 \mathrm{~g} / \mathrm{L}$ of agar is seen to be optimum for the growth of plantlets. Other than that, Sorgato et al. (2020) reported that no presence of charcoal and concentration of agar more than $4.0 \mathrm{~g} / \mathrm{L}$ resulted in better growth of protocorm-like bodies similar to the findings in Figure 3 . Therefore, not only $4.5 \mathrm{~g} / \mathrm{L}$ of agar is suitable for plantlets growth but also is optimal for PLBs.

\section{CONCLUSION}

In a conclusion, the optimization for Grammatophyllum speciosum differs according to the objectives either to generate PLBs or regeneration of plantlets. This study found out that the heaviest PLBs were recorded in the medium containing $1 \mathrm{mg} / \mathrm{L}$ of BAP with the combination of $30 \mathrm{~g} / \mathrm{L}$ of sucrose while for the number of plantlets, the 
highest number recorded was in the medium supplemented with $5 \mathrm{mg} / \mathrm{L}$ of maltose also with $1 \mathrm{mg} / \mathrm{L}$ of BAP. Other than that, this study also discovered that the optimal concentration for agar either for PLBs or regeneration of plantlets was $4.5 \mathrm{~g} / \mathrm{L}$ with $30 \%$ charcoal and $0 \%$ charcoal respectively. The possibilities of this species are endless and the optimization of this study can further improve a better understanding of regarding world's largest orchid, Grammatophyllum speciosum.

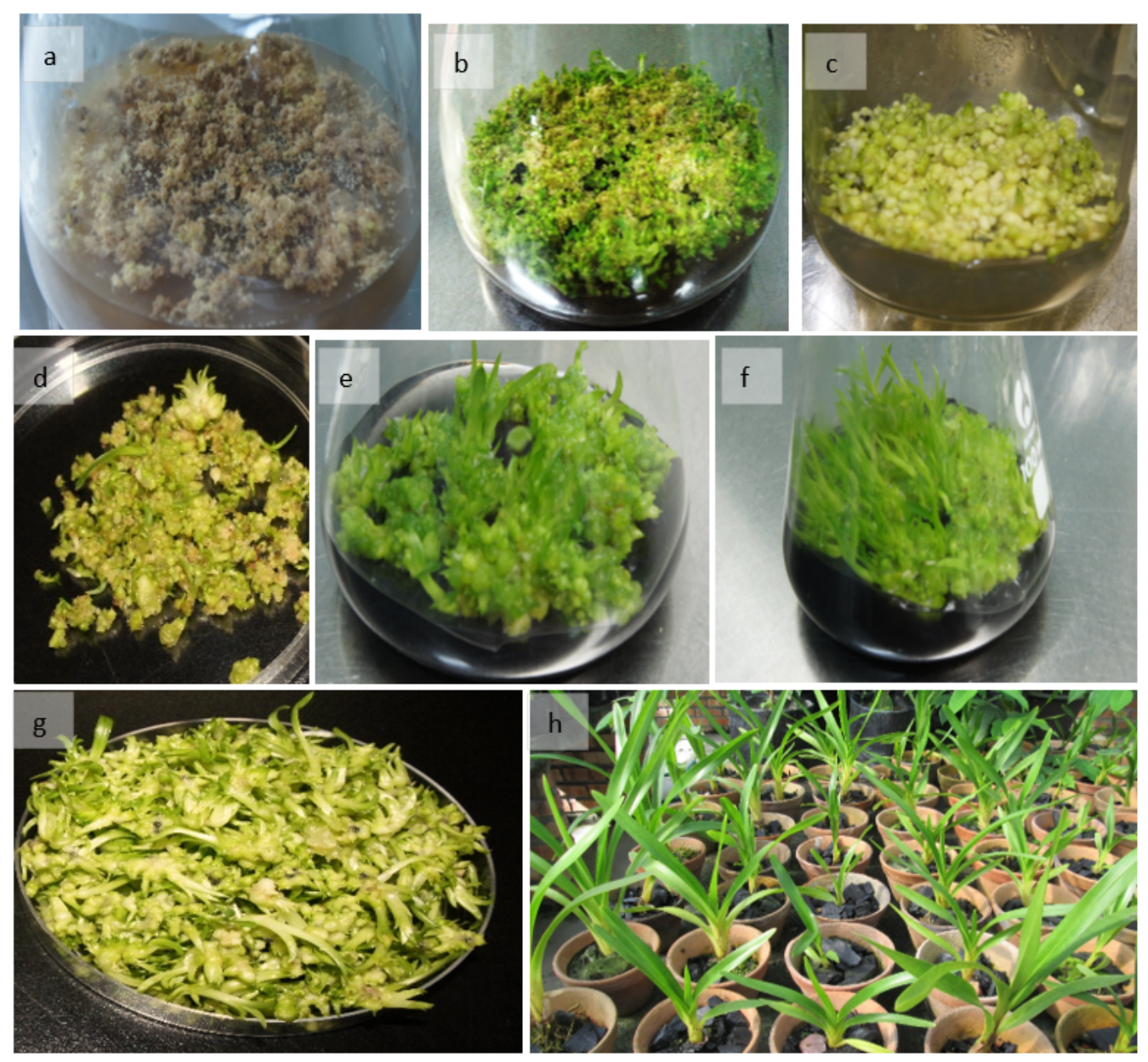

Figure 5 Production of Protocorm-like body and growth ofGrammatophyllum speciosum of tiger orchid. (a) Tiger orchid seeds, (b) seed germination, (c-d) Protocorm Like Bodies (PLB's), (e,f,g ) shoot regeneration and plantlets and (h) three months old plants kept at the glasshouse under $75 \%$ shading.

\section{REFERENCES}

Cardoso, J. C., Zanello, C. A., \& Chen, J.-T. (2020). An Overview of Orchid Protocorm-Like Bodies: Mass Propagation, Biotechnology, Molecular Aspects, and Breeding. International Journal of Molecular Sciences, 21(3), 985-985. Retrieved from https://dx.doi.org/10 .3390/ijms21030985 10.3390/ijms21030985 
Chee, B. (2015). Know Thy Herb : The Tiger Orchid, July.

Debergh, P. C. (1983). Effects of agar brand and concentration on the tissue culture medium. Physiologia Plantarum, 59(2), 270-276. Retrieved from https://dx.doi.org/10.1111/ j.1399-3054.1983.tb00770.x 10.1111/j.1399-3054.1983.tb00770.x

Júnior, D. E., Sasamori, M. H., \& Droste, A. (2014). In vitro propagation of Anathallis adenochila (Loefgr.) F. Barros (Orchidaceae), a species endemic to southern and southeastern Brazil. Acta Botanica Brasilica, 28(4), 489-494. Retrieved from https://dx.doi.org/ 10.1590/0102-33062014abb3158 10.1590/0102-33062014abb3158

Koene, F. M., Amano, E., \& Ribas, L. L. F. (2019). Asymbiotic seed germination and in vitro seedling development of Acianthera prolifera (Orchidaceae). South African Journal of Botany, 121, 83-91. Retrieved from https://dx.doi.org/10.1016/j.sajb.2018.07.01910 $.1016 / j . s a j b .2018 .07 .019$

Luo, J.-P., Wawrosch, C., \& Kopp, B. (2009). Enhanced micropropagation of Dendrobium huoshanense C.Z. Tang et S.J. Cheng through protocorm-like bodies: The effects of cytokinins, carbohydrate sources and cold pretreatment. Scientia Horticulturae, 123(2), 258-262. Retrieved from https://dx.doi.org/10.1016/j.scienta.2009.08.008 10.1016/j.scienta.2009.08.008

Murdad, R., Latip, M. A., Aziz, Z. A., \& Ripin, R. (2010). Effects of carbon source and potato homogenate on in vitro growth and development of sabah's endangered orchid: Phalaenopsis gigantean. Asia-Pacific Journal of Molecular Biology and Biotechnology, 18(1), 197-200.

Orshinsky, B., McGregor, L., Johnson, G. E., Hucl, P., \& Kartha, K. (1990). Improved embryoid induction and green shoot regeneration from wheat anthers cultured in medium with maltose. Plant Cell Reports, 9(7), 365-369. Retrieved from https://dx.doi.org/10.1007/ bf00232400 10.1007/bf00232400

PIMSEN, M., \& KANCHANAPOOM, K. (2011). Effect of Basal Media and Sugar Types on in Vitro Regeneration of Grammatophyllum speciosum Blume. Notulae Scientia Biologicae, 3(3), 101-104. Retrieved from https://dx.doi.org/10.15835/nsb33615310 $.15835 / \mathrm{nsb336153}$

Sanjaya, N., Penna, S., Granstrom, T., \& Tanaka, M. (2007). The influence of different carbon sources, hothetero-, photoauto-, and photomixtrophic conditions on protocorm-like body organogenesis and callus formation in thin cell layer culture of hubrid Cymbidium (Orchidaceae)., 6.

Sipayung, P., Matanari, J., Lafau, M. B., Sulastri, Y. S., Ginting, B. B., Sihombing, D. R., Pandiangan, M., \& Giawa, T. (2018). The effect of activated charcoal dose and benzyl amino purine concentration on the growth of orchid plantlets in murashige and skoog media in vitro. IOP Conference Series: Earth and Environmental Science, 205(1), 012025012025. Retrieved from https://dx.doi.org/10.1088/1755-1315/205/1/012025 10 .1088/1755-1315/205/1/012025

Sopalun, K., Thammasiri, K., \& Ishikawa, K. (2010). Micropropagation of the Thai orchid Grammatophyllum speciosum blume. Plant Cell, Tissue and Organ Culture (PCTOC), 101(2), 143-150. Retrieved from https://dx.doi.org/10.1007/s11240-010-9671-2 10 .1007/s11240-010-9671-2

Sorgato, J. C., Soares, J. S., Damiani, C. R., \& Ribeiro, L. M. (2020). Effects of light, agar, activated charcoal, and culture medium on the germination and early development of Dendrobium seedlings. April 2020, 14(14(04):2020), 557-564. Retrieved from https:// dx.doi.org/10.21475/ajcs.20.14.04.p1528 10.21475/ajcs.20.14.04.p1528

Te-Chato, S., Thammasiri, K., \& Rittirat, S. (2012). Effect of media and sucrose concentrations 
with or without activated charcoal on the plantlet growth of P . cornu-cervi (Breda) Blume \& Rchb.f. Journal of Agricultural Technology, 8(6), 2077-2087.

Thomas, T. D. (2008). The role of activated charcoal in plant tissue culture. Biotechnology Advances, 26(6), 618-631.

Zha, X. Q., Luo, J. P., Jiang, S. T., \& Wang, J. H. (2007). Enhancement of polysaccharide production in suspension cultures of protocorm-like bodies from Dendrobium huoshanense by optimization of medium compositions and feeding of sucrose. Process Biochemistry, 42(3), 344-351. 